\title{
LOS ESPAÑOLES ANTE LA JUSTICIA PENAL: ACTITUDES Y EXPECTATIVAS
}

\section{Carmen Ruidíaz García}

\section{INTRODUCCION ${ }^{1}$}

\begin{abstract}
«Cuantos más vetos y prohibiciones existen, más se empobrece el pueblo; cuantos más arcos justicieros se poseen, más extiende sus rigores el desorden; cuanto más se desarrolla la inteligencia fabril, más espurios son sus productos; cuanto más se multiplican las leyes y ordenanzas, más abundan ladrones y bandidos.»
\end{abstract}

Tao Te king

No hay sociedad ni grupo social que carezca de normas, más o menos formalizadas. Por ello, desde sus orígenes, la sociología ha prestado una atención

${ }^{1}$ Uno de los primeros estudios sociológicos referidos a lo que Friedman (1969) etiquetó como "cultura legal» (conjunto de valores y actitudes existentes respecto del sistema legal) lo realizaron un grupo de estudiosos escandinavos interesados en valorar las opiniones y actitudes del ciudadano medio respecto del sistema legal. Son los denominados estudios KOL (Knowledge and Opinion about Law); sus análisis sirvieron para desarrollar una estrategia de presión sobre la política oficial en materia criminal. Trabajos posteriores de Boydell y Grindstaff (1974) han centrado sus esfuerzos en valorar la congruencia entre la opinión pública, las leyes y su aplicación. Rossi, Waite, Bose y Berk (1974), en base a un estudio previo de Selling y Wolfgang (1964), se interesan por la valoración de los hechos delictivos en una muestra significativa de jueces, poli- 
especial al conjunto de normas sociales que regulan todo tipo de relación social: el derecho. El derecho regula determinadas conductas de los hombres en sociedad, protege derechos, determina obligaciones, prohíbe ciertos comportamientos e impone otros. En esta ocasión no vamos a hablar sobre la explicación o la justificación de estas características, sino sobre la relación mantenida entre el derecho (como sistema normativo institucionalizado en forma de sistema judicial) y los ciudadanos o, más concretamente, trataremos de presentar, por una parte, una imagen nítida de las convicciones colectivas mayoritarias en torno al grado de efectividad de la Justicia, incluida la Justicia penal, y, por otra, lo que la ética social mayoritaria considera permisible o punible.

El derecho penal es el derecho protector de los fundamentos básicos sobre los que se asienta la sociedad (los llamados bienes jurídicos); conocer dónde se sitúa la opinión pública española en el proceso de creación y aplicación de la ley penal (bien para sostener sus convicciones o para intentar cambiarlas) nos parece especialmente útil en un momento de debate público alrededor de la elaboración del Código Penal de la democracia.

En lo sucesivo trataremos de constatar empíricamente dónde se sitúa la opinión pública española en esta materia. Haciendo uso de un análisis fundamentalmente diacrónico ( $\mathrm{y}$ exploratorio), analizaremos si al extenderse en el tiempo la experiencia política democrática se produce un cambio, o una continuidad, de las opiniones y actitudes de los españoles sobre el sistema jurídicopenal de la democracia ${ }^{2}$.

\section{LA JUSTICIA Y SU PUBLICO: IMAGENES Y REPRESENTACIONES SOCIALES}

En 1789, los cahiers de doléance reprochaban a la Justicia su lentitud, su corte exorbitante, su imagen predominantemente hermética, la ignorancia, la

cías y estudiantes en Filadelfia. F. X. Fibordy (1977), por su parte, verifica que el público en general no conoce las instituciones penales. En nuestro país es tardía la preocupación por conocer sistemáticamente la opinión pública (corrientes y estados de opinión) sobre esta materia. No obstante, los análisis realizados por el Centro de Investigaciones Sociológicas, el Consejo General del Poder Judicial y otros organismos públicos y privados demuestran que en España existe una "cultura legal», a pesar de que el grado de conocimiento de la estructura y funcionamiento de la Justicia sea muy reducido. El Centro de Investigaciones Sociológicas ha realizado sistemáticamente estudios relacionados con la Justicia. Ejemplos significativos son: 1978 E. 1.149, "criminalidad»; 1987 E. 1.714, "terrorismo y seguridad ciudadana»; 1982 E. 1.305, «sistema judicial»; 1987 E. 1.708, «la justicia ante la opinión pública»; 1989 E. 1.847, «imagen del jurado».

${ }^{2}$ La Constitución de 1978 nació con una clara vocación garantista. Ya en el preámbulo se proclama la voluntad de consolidar un Estado Social y Democrático de Derecho. Posteriormente, los artículos 1, 9 y 25.2 exponen un programa penal concreto y preciso, marcando pautas sobre la elaboración de las leyes, la política criminal y la ejecución de las penas privativas de libertad. Hoy, tras varios años de desarrollo democrático, los imperativos legales expresados en la Carta Magna han cuajado en la ciudadanía. No obstante, todos los españoles no valoran y entienden estos mandatos de la misma forma. 
arbitrariedad de los jueces. Hoy día, la imagen de la Justicia ante la opinión pública, o ante grandes sectores de ésta, no ha cambiado mucho. Y esto es así porque, conforme acredita una dilatada experiencia histórica, de todas las instituciones del Estado es la judicial la más resistente a la transformación social ${ }^{3}$.

Los años transcurridos desde la entrada en vigor de la Constitución han convertido en un lugar común la afirmación del mal funcionamiento de la Justicia, un fenómeno que no es exclusivo de nuestro país. Como ha señalado J. J. Toharia (1990), en países de sistemas jurídicos tradicionales, tales como Francia o Gran Bretaña, la opinión pública tiende a pensar en la actividad judicial de forma negativa.

Así, y haciendo uso de diagnósticos de tendencia (evolución en el tiempo de los estados de opinión) y de situación (evaluación del funcionamiento actual) de la Justicia, se constata que la Justicia funciona mal.

Por lo que respecta al análisis de tendencia, es decir, la comparación de la Administración de Justicia consigo misma en distintos momentos del tiempo, la mayoría de los encuestados no perciben variaciones importantes (véase cuadro 1) que indiquen una mejora. Entre el resto son algo más numerosos quienes perciben una tendencia a mejorar (17 por 100 en 1990) que quienes perciben un deterioro (11 por 100 en 1990).

Esto implica un leve pero significativo cambio de tendencia: en efecto, hace tan sólo dos años eran claramente más frecuentes quienes percibían un deterioro en el funcionamiento de la Justicia que quienes apreciaban una mejora. Es decir, de un diagnóstico global de «igual tirando a peor» en 1988, hemos pasado a otro de «igual tirando a mejor» en 1990.

Es de destacar que entre los votantes del Partido Popular son más numerosos quienes piensan que en estos últimos años la Justicia ha ido a peor. Entre los votantes de las otras formaciones de ámbito estatal (caso de los votantes del PSOE y, sobre todo, de IU) perciben una mejora en la situación de la Justicia.

3 En España, «el tempo de la justicia, como hubiera sido razonable esperar, no se acomodó mecánicamente al tempo político general... Con la perspectiva que ofrece el transcurso de todos estos años, puede decirse ya que en lo fundamental se operó de forma claramente reduccionista. La cuestión justicia se presentó como puro problema político o, aún más, de puro gobierno judicial. Visión ésta sostenida por una concepción mecanicista de la institución, de la que sería bastante cambiar el piloto para hacer de ella otra». P. ANDrÉs IbÁÑEZ y V. PÉREZ MARIÑo, «La justicia: entre la Constitución y la crisis», en J. Vidal-Beneyto (ed.), España a debate (tomo I), Madrid, Tecnos, 1991, p. 88. Un simple examen superficial de la LOGP de 1985 confirma esta última afirmación. El texto mantiene en términos sustanciales el modelo organizativo de la Ley de 1870 y no aporta ninguna novedad técnica de relieve. También es un dato elocuente el de que el diseño de la justicia penal se hiciera en buena medida sobre un modelo, el del juez monocrático encargado a la vez de la instrucción y el enjuiciamiento, con las desastrosas consecuencias que ahora ya se han experimentado. La Ley Orgánica del Poder Judicial supuso básicamente una apuesta por la conservación, y se encuentra aún pendiente de desarrollo de aspectos fundamentales. Las leyes reguladoras de todos los órdenes jurisdiccionales continúan siendo fundamentalmente las mismas. Los resultados son llamativos, el volumen de asuntos pendientes que pesa sobre la generalidad de los órganos jurisdiccionales alcanza cifras que obligan a dudar seriamente de la posibilidad de una salida previsible de la actual situación». 


\section{CUADRO 1}

En su opinión, y por lo que usted sabe, a lo largo de estos últimos dos o tres años el funcionamiento de la Administración de Justicia española ha...

(En porcentajes)

\begin{tabular}{|c|c|c|c|c|c|}
\hline & & & Años & & \\
\hline & 1984 & 1985 & 1986 & 1988 & 1990 \\
\hline 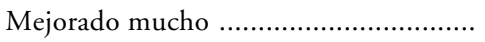 & 4 & 4 & 5 & 3 & 3 \\
\hline 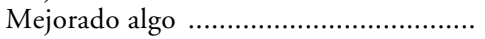 & 21 & 22 & 21 & 16 & 17 \\
\hline Permanecido más o menos igual ........... & 37 & 37 & 41 & 46 & 47 \\
\hline 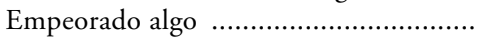 & 12 & 12 & 14 & 17 & 11 \\
\hline 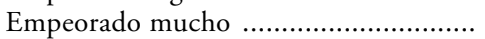 & 7 & 6 & 6 & 8 & 7 \\
\hline 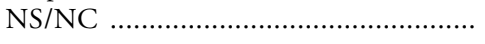 & 19 & 19 & 12 & 19 & 15 \\
\hline (n) & 1.200 & 1.200 & 1.200 & 1.200 & 1.200 \\
\hline
\end{tabular}

Fuente: Barómetros de opinión pública del Consejo General del Poder Judicial.

En cuanto al diagnóstico de situación, es decir, la comparación de la Justicia con otras grandes instituciones del Estado (véase cuadro 2), confirma esta mejora en la evaluación, dentro de un contexto general de valoración más positiva que hace dos años del funcionamiento institucional del Estado. En efecto, el funcionamiento actual de los Tribunales de Justicia (expresado por medio de una puntuación entre 1 -muy mal-y 5 -muy bien-) alcanza ahora una puntuación media de 2,69, que, si bien es claramente inferior a las obtenidas en $1984(2,98)$ y $1985(2,88)$, es, en cambio, más elevada que la correspondiente a $1986(2,58), 1988(2,62)$ y $1990(2,69)$, confirmando la tendencia a una lenta y gradual mejora en la imagen de la Justicia tras un importante bache en años recientes.

Por otra parte, los votantes del PSOE son quienes en mayor proporción evalúan positivamente el funcionamiento de las seis instituciones básicas consideradas. Por el contrario, los votantes del Partido Popular son quienes en mayor proporción las califican negativamente.

¿Cuáles son las posibles explicaciones (o causas) de la insatisfacción en torno al funcionamiento de la Justicia? ${ }^{3}$

4 «La conexión causal entre dos acontecimientos no involucra ningún poder o fuerza que haga del efecto una consecuencia necesaria de la causa... La observación repetida de la asociación de dos eventos nos lleva al hábito de esperar que la asociación continúe repitiéndose en el futuro.» A. GARCía SuÁreZ, Introducción al libro de M. BLACH, Inducción y probabilidad, Madrid, Alianza Universidad, 1979, p. 25. Conviene comenzar diciendo que, en el tema que nos ocupa, las explicaciones causales no son las únicas posibles. De igual manera podríamos buscar explicaciones funcionales o teleológicas, nomológicas o estadísticas. Para entendernos, usaremos aquí el 


\section{CUADRO 2}

Por lo que usted pueda saber, ¿cómo puntuaría usted entre 1 («muy mal») y 5 («muy bien») la forma en que funcionan hoy en España ...

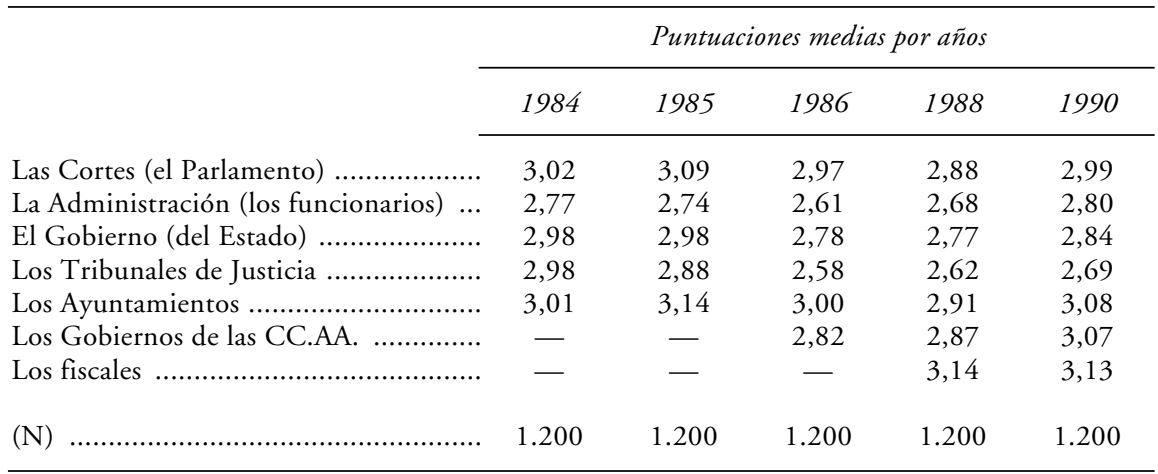

Fuente: Barómetros de opinión pública del Consejo General del Poder Judicial.

Varias son las causas que los estudiosos del problema han señalado para explicar el fenómeno de la mala prensa de la Justicia: la lentitud, el secretismo, la obsolescencia de las instituciones judiciales, la corrupción, el coste económico, la impredecibilidad de las resoluciones dictadas y la falta de eficacia a la hora de la ejecución de las sentencias. A la vista de estos datos, y sin pretensiones de exhaustividad, haremos referencia a algunos de estos problemas.

\section{Los recursos de la Administración de Justicia. Imparcialidad, coherencia y trato recibido de la Justicia}

En los últimos años se han concentrado importantes mejoras en la dotación de medios (materiales y personales) en la Administración de Justicia. La opinión pública parece ser claramente sensible a ello. En 1988, el 53 por 100 de los españoles consideraban que la Justicia española no contaba con los medios precisos para realizar su labor; dos años después, esa respuesta sigue siendo elevada, aunque con tendencia a la baja (38 por 100). Estos datos parecen sugerir que entre la ciudadanía española se ha amortiguado la sensación de carencia de la Justicia, pero sin que al mismo tiempo se haya consolidado la certeza de que, efectivamente, cuenta ya con los medios precisos para funcionar adecuadamente.

término de "causa» no sólo como mera asociación de acontecimientos, sino en el sentido de condición necesaria, aun cuando no suficiente, de un efecto y hablaremos así de multicausalidad. 
La política del Estado actual tiende a crear una situación en donde una parte significativa de las contradicciones existentes en el pretendido Estado social se resuelven por los órganos judiciales.

No obstante, y pese al incremento de la litigación y el mayor uso de los Tribunales de Justicia, el 45 por 100 de los españoles piensan que nuestros Tribunales no son imparciales, frente al 37,2 por 100 que consideran que sí lo son. Esta pauta es justamente la inversa a la detectada en 1988 y 1985 , y ello parece sugerir que, en este punto, la opinión pública experimenta fuertes oscilaciones en función, sin duda, de la resonancia que puedan en cada fecha haber alcanzado causas o sentencias muy específicas. Por ejemplo, sendos estudios del CIRES - 1988 y 1990 — se efectuaron poco tiempo después de hacerse públicas sentencias de amplia difusión en los medios de comunicación de masas. En 1988 coincidió con las sentencias que condenaban por corrupción a determinados policías y magistrados, caso «El Nani» y caso del aceite de colza. En 1990 el estudio se efectuó en plena polémica de los llamados casos Juan Guerra y Naseiro, factores contextuales que no se pueden obviar a la hora de valorar los datos de encuesta.

Por lo que respecta al grado de coherencia en la actuación de los Tribunales, la inmensa mayoría de los entrevistados (el 84 por 100) se siente en condiciones - al margen de que objetivamente pueda o no estarlo- de emitir una opinión sobre esta cuestión.

Según los resultados del quinto barómetro de opinión pública del CGPJ, las opiniones aparecen muy divididas con un cierto predominio de las valoraciones críticas. En efecto, para un 24 por 100, los Tribunales españoles suelen ser muy o bastante coherentes (es decir, sentencian de forma igual los casos que son iguales), pero para un 26 por 100 lo son poco o muy poco.

Entre la mitad y dos tercios de los entrevistados en cualquier segmento social piensan que el caso por el que tuvieron relación con la Justicia se resolvió de forma justa, pero sólo entre un tercio y menos de la mitad opinan que se resolvió en un plazo razonable, aunque en este supuesto la proporción que cree que se resolvió en un plazo razonable supera a la que no lo cree así en varios segmentos sociales (mayores de 65 años, baja posición social, centro, no han sido víctimas de ningún delito y creen en la independencia de los jueces), los mismos que afirman también en proporción mayor que su caso se resolvió de forma justa. Así, pues, la opinión predominante de quienes han tenido relación directa con la Justicia parece positiva respecto a la forma en que se resolvió su asunto, pero no tanto respecto al plazo de resolución.

Si comparamos la percepción subjetiva del trato recibido en la Administración de Justicia y otros organismos públicos, no parece que los entrevistados perciban importantes diferencias de trato. Alrededor del 60 por 100 , tanto en 1988 como en 1990 , creen que el trato dispensado es igual en los organismos públicos que en los Tribunales de Justicia.

Finalmente, y utilizando una serie de afirmaciones sobre la Justicia, se pone de relieve que más de tres cuartas partes de los españoles de 18 y más 
años están de acuerdo en que «las decisiones de los Tribunales son tan lentas que vale más evitar pleitear», y que "el pleitear es tan caro que, en general, acaba por no compensar el hacerlo». Sólo una mayoría, cercana pero inferior al 50 por 100 de los entrevistados, está de acuerdo en que «en general, los jueces ejercen su función de forma íntegra y honesta». Estas opiniones son compartidas por todos los segmentos sociales, sin que se observen diferencias significativas en ningún caso, en función de la edad, sexo, tendencia ideológica o nivel de estudios de los entrevistados. Ahora bien, estas opiniones son extrapolables a toda la población, de lo que se desprende una imagen negativa de la Justicia, se la considera lenta, cara y poco eficiente.

No obstante, y pensando en el futuro, observa J. Díez Nicolás (1990) que todos los entrevistados son muy optimistas respecto al previsible funcionamiento de los Tribunales de Justicia dentro de dos o tres años.

\section{Ineficacia en la lucha contra el delito.}

La reacción social ante la inseguridad y la delincuencia ${ }^{5}$

En nuestro país, la primera encuesta de victimización se realizó en julio de 1978 (CIS, E. 1.149). El informe sobre sus resultados dice textualmente: "llama la atención el elevado porcentaje de personas que no se sienten seguras (36 por 100) y el hecho de que sean los niveles de renta baja y educativos altos los que más inseguros se sienten ( 44 y 40 por 100 , respectivamente)». Una situación similar, reconocían los redactores del informe, a la de otros países de nuestro entorno cultural como Alemania o Francia.

En dicho informe se constata igualmente que el 11 por 100 de los entrevistados manifiestan haber sido víctimas de delito a lo largo de su vida. Las diferencias más importantes se observan en el tamaño del municipio de residencia (Madrid y Barcelona contemplan las tasas de victimización más altas). Los datos parecen sugerir de forma muy clara que la proporción de quienes han sido víctimas de algún delito es mayor cuanto menor es la edad del entrevistado y cuanto mayor es su posición social y el estatus socioeconómico familiar, es decir, que la relación que se establece coincide básicamente con la observada al analizar el contacto personal con el mundo de la Justicia.

${ }_{5}$ El miedo se ha convertido en un denominador común de la cultura moderna y, posiblemente, un factor fundamental de cohesión social. En la mayoría de los países, la preocupación por la seguridad personal se ha convertido en uno de los problemas sociales a resolver. Sabemos, y así lo indican con constancia todos los barómetros de opinión, que, después del paro y en conexión con el terrorismo, la inseguridad ciudadana (entendida como miedo al delito) es una de las mayores preocupaciones para el conjunto de los ciudadanos de las sociedades modernas. «El miedo a los asaltos, a los robos, atracos, a las violaciones, en fin a la violencia callejera, y el temor a los atentados terroristas, han sustituido hoy a los viejos temores que despertaban antaño la lepra y la peste, los anuncios apocalípticos del fin del mundo, las terribles penas del infierno.» F. Alvarez Uría y J. Varela, Sujetos frágiles, México, FCE, 1989, p. 132. 
Hasta aquí, todo en orden. Estamos en los inicios del delirio securitario y, aunque muchos ciudadanos empiezan a sentirse inseguros, todavía más del 50 por 100 de los españoles no padece paranoias ni miedos irracionales. El miedo es libre e incontrolable, como siempre, pero al menos tiene todavía una base racional; se sienten más inseguros quienes más probabilidades tienen de ser víctimas de un delito.

Varios años después, la sensación de inseguridad y las tasas de victimización han crecido considerablemente, sobre todo si se toman en consideración las tasas de victimización registradas por amigos o familiares próximos al entrevistado (en 1987, E. 1.714, el 40 por 100 de los encuestados manifiestan que algún amigo o pariente próximo ha sido víctima de delito; varios años después, las cifras siguen siendo similares: en 1992, el 41 por 100 mantienen esta opinión). Como indican acertadamente F. Alvarez Uría y J. Varela, "para que el sentimiento de temor se consolide no es suficiente la amenaza, es preciso que esa amenaza se haga realidad $\aleph^{6}$.

Si confrontamos las estadísticas de criminalidad (número de delitos conocidos por la Guardia Civil y la Policía Judicial: 1978, 350.423; 1992, 934.070) con la imagen que tiene la población del incremento de la criminalidad, los resultados indican que una parte importante de la población consultada cree que la criminalidad está en aumento.

Esta sensación refuerza la cuestión precedente del sentimiento de inseguridad. El porcentaje de sujetos que consideran que la criminalidad está en aumento crece ligeramente en función del grupo de edad y es más importante en el grupo de edad superior. Y son las mujeres las que estiman de una forma más elevada que los hombres el aumento de la delincuencia.

Unido a esta sensación de amenaza, los ciudadanos no se sienten protegidos frente al delito. Más de la mitad de los entrevistados en 1988 y 1990 no se consideran adecuadamente protegidos frente a los delincuentes (véase cuadro 3).

Esta apreciación negativa está en consonancia con la insatisfacción que sienten los españoles con la actuación de las instituciones públicas en el mantenimiento del orden y la seguridad ciudadana; los encuestados no se encuentran satisfechos de su actuación, las consideran ineficaces. No obstante, y tal como queda reflejado en el cuadro 4, la policía es la institución mejor valorada por los españoles sin distinción de edad, sexo, nivel de estudios o tendencia ideológica.

La insatisfacción con las instituciones de control puede tener, y de hecho tiene, consecuencias para la vida ciudadana. Este desconcierto y desencanto puede desencadenar una histeria colectiva. Como indica A. Elorza, «en una democracia no hay amenaza más grave que la incapacidad del sistema para conectar con la sociedad civil»?

En 1987, el CIS, E. 1714, preguntaba a los españoles si habían tomado

${ }^{6}$ F. Alvarez Uría y J. Varela, Sujetos frágiles, México, FCE, 1989, p. 132.

7 Entrevista a A. Elorza, Rev. Alfoz, 37, p. 13. 


\section{CUADRO 3}

¿Se siente usted adecuadamente protegidola frente

a los delincuentes y criminales?

\begin{tabular}{|c|c|c|}
\hline & 1988 & 1990 \\
\hline . & 3 & 3 \\
\hline Más bien sí ......... & 14 & 17 \\
\hline A veces sí, a veces no ......................... & 27 & 30 \\
\hline 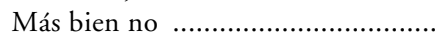 & 28 & 26 \\
\hline No, en absoluto & 27 & 21 \\
\hline 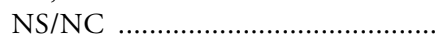 & 2 & 4 \\
\hline$(\mathrm{N})$ & 1.200 & 1.200 \\
\hline
\end{tabular}

Fuente: Barómetros de opinión pública del Consejo General del Poder Judicial.

\section{CUADRO 4}

¿Cómo valoraría usted la actuación de los siguientes individuos o instituciones en la lucha contra la delincuencia?

\begin{tabular}{|c|c|c|c|c|}
\hline & $\begin{array}{l}\text { Muy bien } \\
\text { y bien }\end{array}$ & Regular & $\begin{array}{c}\text { Mal } \\
\text { y muy mal }\end{array}$ & $N S / N C$ \\
\hline Ministerio Interior .............................. & 16 & 39 & 23 & 22 \\
\hline Los jueces & 13 & 37 & 29 & 21 \\
\hline La policía .................................... & 33 & 35 & 16 & 16 \\
\hline 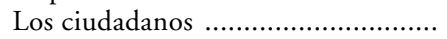 & 30 & 34 & 15 & 21 \\
\hline
\end{tabular}

Fuente: Encuesta Centro de Investigaciones Sociológicas E. 1.736-1988.

medidas para proteger su persona, el domicilio o sus bienes personales. Contestaban afirmativamente un 18 por 100 , frente al 82 por 100 que aseguraban no haber tomado ningún tipo de medidas para protegerse del delito. Curiosamente, los que decían haber tomado medidas eran en mayor medida personas autocalificadas de derechas, con estudios superiores y residentes en municipios urbanos.

Por lo que respecta al tipo de medidas individuales adoptadas para protegerse del delito, los entrevistados manifiestan haber tomado "todo" tipo de medidas, es decir, desde el aprendizaje de prácticas deportivas de combate hasta la adquisición de armas, perros, sistemas de alarma, cerraduras, cadenas, rejas e incluso otro tipo de medidas indirectas tales como invitar a familiares o 
amigos a que vigilen la casa cuando están de vacaciones, no tener objetos de valor en casa o evitar llevar consigo importantes sumas de dinero.

En suma, todo vale para protegerse del delito. Y esto lo ven así la mayoría de los españoles, que, si en un principio manifiestan no haber tomado medidas para evitar ser víctimas de delito, también piensan que es razonable y útil optar por soluciones colectivas como las patrullas ciudadanas de autodefensa que, con cierta frecuencia, aparecen en barrios de las grandes ciudades.

Nuevamente el CIS, E. 1.736, nos permite contrastar las opiniones de los españoles sobre la actuación de estas patrullas de autodefensa y vigilancia nocturna en la lucha contra el delito.

Las estadísticas nos indican que el 52 por 100 de los españoles pensaban que esta solución era razonable. Igualmente conviene resaltar que jubilados y pequeños empresarios son los colectivos que mejor valoran la actuación de las patrullas autodefensivas.

\section{LA CULTURA JURIDICO-PENAL DE LOS ESPAÑOLES ${ }^{8}$}

Conviene recordar que el orden social no es monolítico y uniforme. La existencia de subgrupos, minorías o subculturas implica que coexisten múltiples códigos de valores (no existe un único código axiológico). Por tanto, no se puede esperar que las valoraciones y actitudes de la opinión pública sean homogéneas y uniformes.

No pretendemos dar consistencia empírica a esta afirmación. Por el momento, y dada la dificultad técnica de un estudio sobre el universo axiológico de una colectividad, nos conformamos con plasmar algunos resultados extraídos de distintos estudios de opinión sobre la valoración de algunos ejemplos nodales.

${ }^{8}$ El orden social no es únicamente orden jurídico, ni puede mantenerse sólo mediante la coacción; también precisa del consentimiento y el interés de los ciudadanos para su supervivencia. Es posible que un régimen pueda persistir durante un período más o menos largo apoyado en la fuerza, el temor y la indiferencia. Pero cuando una mayoría de los ciudadanos no comprenden y aprueban el orden establecido, la sociedad se debate en continuas crisis. Si a esto se añade que existen grupos, o subgrupos, de presión que intentan abrirse paso y autoafirmarse apoderándose del poder de "definir», es decir, del poder de reflejar en las decisiones legislativas sus propias definiciones, y el de mediatizar o influir en las instancias y mecanismos de control y criminalización (creando un clima sociológico apropiado a sus intereses, tanto antes como después de crear una norma), no puede extrañar que la opinión pública se decante mayoritariamente hacia una orientación (predefinida por los grupos de interés) en el proceso de penalización y despenalización. Partiendo de este supuesto, hemos de reconocer que los criminólogos críticos tienen parte de razón al afirmar que, en la criminalización primaria (creación de la norma), se reproduce el universo moral de la cultura burguesa individualista, protegiendo - a veces en exceso- el patrimonio privado y controlando formas de desviación típicas de los grupos sociales más débiles y marginados, dejando al descubierto, o sin protección penal, determinadas áreas de gran repercusión social, tales como los delitos económicos (es difícil distinguir entre una colosal estafa y un gran negocio) o delitos ecológicos. 
Los españoles y las leyes

Los españoles tienden a valorar positivamente la existencia de leyes. Distintos estudios de opinión pública han demostrado que el derecho se ha convertido en una parte importante e imprescindible de la vida social. Así lo entienden la mayoría de los encuestados, los cuales piensan que las normas (reglas y leyes) son imprescindibles para el buen funcionamiento de la sociedad.

No obstante, y pese a la importancia otorgada a las leyes para el buen funcionamiento de la sociedad, muy pocos españoles saben con precisión quién las hace y cómo se elaboran las leyes (véase cuadro 5).

Los españoles no tienen una conciencia clara de los mecanismos de creación de las leyes. En 1987, sólo el 39 por 100 de los encuestados piensan que las leyes son elaboradas por las Cortes, en tanto que un 3 por 100 piensan que las hace el Rey, un 43 por 100 que las elabora el Gobierno y el 15 por 100 restante no sabe o no quiere dar una respuesta a esta pregunta.

Si comparamos estos datos con los referidos a 1982 (véase cuadro 5) se observa que ha avanzado la consideración de que las leyes las hace el Gobierno (15 puntos porcentuales), dato que, si bien no es acertado desde un punto de vista técnico-jurídico constitucional, se ajusta más a la realidad, dado que, en un sistema democrático representativo como el nuestro, las Cortes son las que elaboran las leyes, pero el Gobierno tiene iniciativa legal y las leyes se hacen normalmente a partir de un proyecto de ley presentado por el Gobierno. Si a esto unimos que la mayoría absoluta de las cámaras legislativas ha estado en

\section{CUADRO 5}

Si un amigo extranjero le preguntase quién hace

las leyes en España, ¿qué le contestaría usted?

\begin{tabular}{|c|c|c|}
\hline & 1982 & 1987 \\
\hline 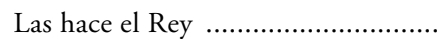 & 5,0 & 2,6 \\
\hline Las hace el Gobierno .......... & 28,0 & 43,4 \\
\hline Las hacen las Cortes ............................. & 48,0 & 39,2 \\
\hline NS & 16,0 & 13,7 \\
\hline NC & 3,0 & 1,0 \\
\hline$(\mathrm{N})$ & 4.985 & 2.499 \\
\hline
\end{tabular}

FuENTE: Encuestas CIS E. 1.305-1982; E. 1.708-1987.

9 Las leyes no sólo tienen la función penal de imponer sanciones a los que cometen delitos, sino que tienen también la función, igualmente importante, de garantizar los derechos y defender las libertades de los ciudadanos a través del aparato judicial. 
estos años estrechamente cohesionada con el Gobierno puede, sin duda, contribuir a incrementar, tal como lo reflejan los datos, la impresión y el sentir generalizado de que es el Gobierno quien hace las leyes.

No obstante, y aun aceptando esta explicación, no deja de alarmarnos que tanto en 1982 como en 1987 los españoles con estudios medios y superiores sigan teniendo una visión confusa de quiénes son los que elaboran la ley.

No parece oportuno resucitar el viejo debate de por qué los españoles tienen este bajo conocimiento de lo «jurídico»; el discurso nos llevaría por derroteros distintos de los que perseguimos con estas líneas. Por ello, y haciendo uso de las encuestas de opinión, nos interesa plasmar el sentir de los españoles respecto a la obediencia o desobediencia de las leyes y su visión de la equidad o justicia con que son aplicadas las leyes (véase cuadro 6).

\section{CUADRO 6}

Grado de acuerdo con las siguientes frases

(Se han agrupado las respuestas "Muy de acuerdo» $\mathrm{y}$ "Bastante de acuerdo». En porcentajes)

\begin{tabular}{|c|c|c|c|c|c|c|c|}
\hline \multirow[b]{3}{*}{$\begin{array}{l}\text { Las leyes deben ser obedeci- } \\
\text { das simplemente porque } \\
\text { son leyes ................................. }\end{array}$} & \multicolumn{7}{|c|}{ Años } \\
\hline & 1978 & 1980 & 1982 & 1984 & 1986 & 1988 & 1990 \\
\hline & 64 & 64 & 57 & 62 & 47 & 45 & 40 \\
\hline $\begin{array}{l}\text { No debemos obediencia más } \\
\text { que a las leyes razonables .. }\end{array}$ & 47 & 36 & 35 & 23 & 46 & 40 & 36 \\
\hline$(\mathrm{N})$ & 1.200 & 1.200 & 1.200 & 1.200 & 1.200 & 1.200 & 1.200 \\
\hline
\end{tabular}

Fuente: Barómetros de opinión pública del Consejo General del Poder Judicial.

A juzgar por los datos de opinión de que disponemos, más del 50 por 100 de nuestros conciudadanos piensan que las leyes no se respetan, y no se respetan porque, para una amplia mayoría, sólo las leyes razonables y buenas deben ser obedecidas.

La opinión pública cree, mayoritariamente, que los españoles obedecemos las leyes poco o muy poco, y esa opinión predomina en todos los segmentos sociales, pero más intensamente aún entre los menores de 30 años y los mayores de 65 años, entre los de baja posición social, entre los que se autositúan en la derecha y entre quienes no creen en la imparcialidad de las leyes ni en la independencia de los jueces. 
En 1982, el 69,4 por 100 de los entrevistados en una encuesta nacional, E. 1.304, manifestaban que "las leyes sólo benefician y protegen a unos pocos»; cinco años después, E. 1.078, el porcentaje sólo se reduce ligeramente. El 61,4 por 100 pensaban que las leyes son desiguales e injustas. Igualmente persistía esta percepción negativa a la hora de valorar la aplicación de la ley. El 74,8 por 100 de los entrevistados manifestaban que al aplicar las leyes «se hacen diferencias según de quién se trate».

Haciendo referencia al año 1987, E. 1.708, debe resaltarse que sólo un 13 por 100 de los españoles de 18 y más años opinan que las leyes consideran a todos los ciudadanos por igual, frente a más de un 80 por 100 que opinan que benefician a unos ciudadanos más que a otros. Esta desconfianza tan grande en la imparcialidad de las leyes es compartida por todos los segmentos sociales, sin excepción, y constituye un indicador bastante desalentador respecto a la opinión de los españoles sobre la «justicia» de las leyes.

Coherentemente con esta actitud, sólo un 9 por 100 de los entrevistados cree que el trato que se da en España a los individuos al aplicar las leyes es el mismo para todos, frente a más del 85 por 100 que opinan que el trato es diferente según de quién se trate. Esta opinión es compartida por todos los segmentos sociales. En un estudio más reciente, 1992, E. 2.015, el 15 por 100 de los encuestados por el CIS sigue manteniendo que el trato que se da a los individuos en la aplicación de la ley es desigual, y un 76 por 100 considera que se hacen diferencias según de quién se trate ${ }^{10}$.

\section{La visión de los delitos ${ }^{11}$}

Distintas investigaciones coinciden en valorar que existe un acuerdo general por grupos de edad, sexo, nivel económico, educativo, cultural o tendencia ideológica respecto a la gravedad de algunas tipologías delictivas. En el caso español, los datos de opinión demuestran que los españoles, sin distinción de sexo, edad, nivel económico o cultural, consideran los delitos contra las personas de mayor gravedad que los que atentan contra la propiedad, ya sea individual o colectiva.

Véase el cuadro 7, en el que se indica un pronunciamiento de los entrevistados sobre la gravedad de distintas infracciones.

${ }^{10}$ A poco que pensemos en las leyes, nos encontramos juzgándolas según patrones éticos. Defendemos nuestra posición con argumentos e intentamos rebatir los razonamientos de nuestros oponentes. La mayoría de nosotros no estamos muy seguros de qué principios deben inspirarnos para juzgar las leyes y la conducta en general. Somos partidarios de la libertad, la igualdad, el bien común, pero no sabemos a ciencia cierta lo que esos conceptos significan ni cómo deberían formularse unos principios bien fundamentados; ni siquiera sabemos si se pueden defender razonablemente los principios morales.

${ }^{11}$ Por mucho que se intente, es difícil encontrar una definición sustancial del delito que vaya más allá de la transgresión de la ley establecida. Para decirlo en otras palabras, la existencia del término "delito» depende de la presencia de leyes sociales que puedan ser transgredidas, y éstas varían según las circunstancias de tiempo y de lugar. 


\section{CUADRO 7}

\section{Valoración media de la gravedad apreciada en los siguientes delitos}

\begin{tabular}{|c|c|}
\hline & $\begin{array}{l}\text { Gravedad media } \\
\text { atribuida }\end{array}$ \\
\hline Robo o atraco con asesinato & 9,6 \\
\hline Violación & 9,5 \\
\hline 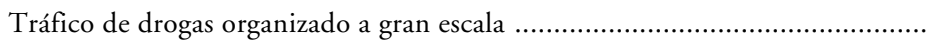 & 9,5 \\
\hline Atraco a mano armada en la calle con heridas o lesiones graves ......................... & 9,0 \\
\hline 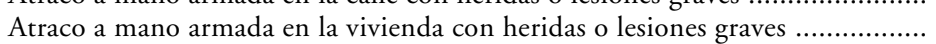 & 8,9 \\
\hline 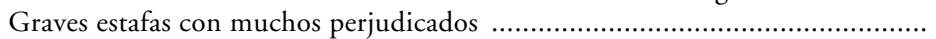 & 8,5 \\
\hline 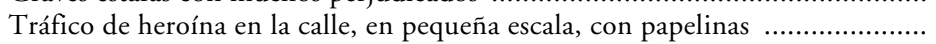 & 8,4 \\
\hline Delitos económicos con enriquecimiento rápido & 7,8 \\
\hline Delitos fiscales o fraude a Hacienda & 7,3 \\
\hline Atraco de un navajero en la calle, en el que nadie resulta herido & 7,0 \\
\hline Robo de un bolso por el sistema del tirón & 6,3 \\
\hline Robo del coche & 6,1 \\
\hline Fraudes y estafas sin violencia. & 6,1 \\
\hline Robo de objetos en su vivienda & 6,1 \\
\hline$(\mathrm{N})$ & 1.200 \\
\hline
\end{tabular}

FUENTE: Encuesta Centro de Investigación sobre la Realidad Social (CIRES), 1991.

Es de destacar que el robo o atraco con asesinato, la violación y el tráfico de drogas a gran escala merecen la máxima gravedad en la opinión pública española; por otra parte, al contrario, las acciones de menor gravedad son las infracciones consideradas como delitos menores tales como robo de coches o de viviendas.

Sin embargo, y aun reconociendo que existe un consenso básico al valorar la gravedad de las infracciones, también tenemos que reconocer que la opinión pública se muestra claramente confusa ante el fenómeno de la penalización y despenalización de determinados comportamientos.

Ante estas apreciaciones, cabe preguntarse: ¿qué hacer entonces a la hora de elaborar una ley, tanto para crear como para derogar?, ¿tendremos que tener en cuenta los estados y corrientes de opinión? A nuestro juicio, sí, pero tomando en consideración un sabio consejo de M. a Jesús Miranda: a la hora de elaborar una ley con el fin de normalizar una práctica social muy extendida, hay que tener en cuenta tres cosas: lo que hace la gente en realidad, lo que dice sobre lo que hace y lo que debe decir la ley para que la diferencia entre las tres sea la mínima.

Los especialistas de la Justicia se sienten tentados a tomar las respuestas al pie de la letra y olvidan que, para la gente normal, la Justicia es un mundo misterioso, remoto, del cual no poseen ninguna práctica. Con las palabras que 
transmiten los medios de comunicación y también los cuestionarios, aquellos especialistas intentan explicar no opciones técnicas exactas, sino reacciones afectivas o preferencias normativas. Sus respuestas son "modos de decir» cuyo sentido queda por descifrar. Siendo así, pedir una mayor severidad no siempre significa pedir encarcelamientos más prolongados — se desconoce la escala de penas realmente practicada-, sino que puede servir, simplemente, para explicar la indignación, el sentimiento de injusticia o incluso el desconcierto.

\section{La pena como castigo. La pena de muerte.}

Institución carcelaria y alternativas a las penas de prisión $n^{12}$

Para medir la severidad de la opinión pública hay que conocer su severidad ante la sanción. Los datos de encuesta demuestran que existe una tendencia general a solicitar una mayor represión y control del delito. Por ejemplo, más del 73 por 100 de los encuestados por el CIS en 1988, E. 1.736, pensaban que no se castiga lo suficiente a los delincuentes; en 1992, E. 2.015, los datos son muy similares (véase cuadro 8).

\section{CUADRO 8}

En su opinión, ¿se castiga en la actualidad suficiente a los que cometen delitos?

\begin{tabular}{|c|c|c|c|c|}
\hline & 1982 & 1988 & 1990 & 1992 \\
\hline 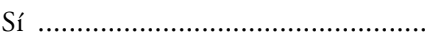 & 28 & 15 & 23 & 17 \\
\hline No & 53 & 73 & 65 & 70 \\
\hline 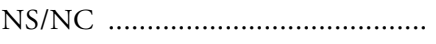 & 19 & 12 & 12 & 13 \\
\hline$(\mathrm{N})$ & 4.985 & 2.500 & 2.492 & 2.498 \\
\hline
\end{tabular}

Fuente: Actitudes de los españoles ante la Administración de Justicia, CIS, Madrid, 1994, p. 42.

Reforzando esta apreciación, distintos sondeos de opinión pública muestran que hay una corriente de opinión partidaria de una idea vengativa en el castigo, «ojo por ojo y diente por diente». Investigaciones realizadas en países de nuestro entorno cultural han mostrado que la norma de retribución se ve fuertemente apoyada por la opinión pública, sin perjuicio del apoyo a la idea de rehabilitación para los delincuentes más jóvenes. Otros indican que las per-

12 La transgresión de la norma se penaliza tanto en las sociedades desarrolladas como en las primitivas. En ambos casos, parte de la sociedad reacciona contra una forma de conducta que es así aprobada o censurada. Pero en nuestras sociedades la sanción está organizada y materializada en el derecho penal y es respaldada por una autoridad con poder para hacer cumplir sus decisiones. 
sonas partidarias de una línea más dura se encuentran en los estratos más bajos en la escala social, así como entre la tercera edad y las mujeres.

En España, la población considera que se deben tomar medidas asistenciales y sociales para erradicar la delincuencia, pero también estima que la represión y el control pueden ser medidas eficaces. La aceptación o el rechazo de unas y otras depende del tipo de delito, el delincuente, el daño causado y la misma sensación de seguridad o inseguridad ante el delito (véase cuadro 9).

Los datos de encuesta nos vuelven a presentar a una opinión pública divi-

\section{CUADRO 9}

Grado de acuerdo con las siguientes frases

(Se han unido las respuestas "Muy de acuerdo» $\mathrm{y}$ "Bastante de acuerdo». En porcentajes)

\begin{tabular}{|c|c|c|c|c|c|c|}
\hline & \multicolumn{6}{|c|}{ Años } \\
\hline & 1984 & 1985 & 1986 & 1987 & 1988 & 1990 \\
\hline $\begin{array}{l}\text { Habría que restablecer la pena de } \\
\text { muerte para algunos delitos ............ } \\
\text { Con más mano dura se acabaría con el }\end{array}$ & 37 & 38 & 40 & - & 39 & 39 \\
\hline $\begin{array}{l}\text { Con más mano dura se acabaría con el } \\
\text { problema de la criminalidad ........... } \\
\text { En ningún caso puede estar justificado }\end{array}$ & - & - & - & 69 & 55 & 56 \\
\hline tomarse la justicia por su mano ...... & - & - & - & - & 59 & 50 \\
\hline
\end{tabular}

Fuente: J. J. TOHARIA, «Quinto barómetro de opinión del Consejo General del Poder Judicial», Poder Judicial, núm. 19, p. 114.

dida y alejada de las propuestas contempladas en el Anteproyecto de Código Penal. Incluso si se toman en consideración las respuestas a la idea de que habría que restablecer la pena de muerte para algunos delitos, nos alejamos totalmente de los principios establecidos en la Constitución española de 1978.

Como es bien sabido, el Anteproyecto de Código Penal establece tres tipos de penas: privativas de libertad, privativas de derechos y multas. Por lo que respecta a las penas privativas de libertad, la duración mínima será de seis meses y la máxima de veinte años. Los datos de encuesta nos vuelven a sorprender. Para una amplia tabla de delitos, los españoles optan por imponer penas superiores a veinte años. Los casos más llamativos son el de robo o atraco con asesinato, con un 36,2 por 100 de la opinión pública favorable a imponer una pena de prisión de veintiuno a treinta años, y la violación, con un 34,3 por 100 de los encuestados que también aprueban la idea de imponer una pena de veintiuno a treinta años, cuando el Anteproyecto establece una pena máxima de ocho años. Igualmente aparecen minorías significativas favorables al restablecimiento de la pena de muerte (véase cuadro 10 ). 
CUADRO 10

De los posibles castigos anotados en esta tarjeta, ¿cuál considera usted justo y adecuado en cada caso?

\begin{tabular}{|c|c|c|c|c|c|c|c|c|}
\hline & $\begin{array}{l}1 \text { a } 6 \\
\text { meses }\end{array}$ & $\begin{array}{l}6 \text { meses } \\
\text { a } 1 \text { año }\end{array}$ & $\begin{array}{l}1 \text { año } \\
\text { a } 3 \text { años }\end{array}$ & $\begin{array}{l}4 \text { a } 8 \\
\text { años }\end{array}$ & $\begin{array}{l}9 \text { a } 18 \\
\text { años }\end{array}$ & $\begin{array}{l}19 \text { a } 20 \\
\text { años }\end{array}$ & $\begin{array}{l}21 \text { a } 30 \\
\text { años }\end{array}$ & $\begin{array}{c}\text { Pena } \\
\text { de muerte }\end{array}$ \\
\hline $\begin{array}{l}\text { Robo de objetos en vivienda (desvalijar, rotura de muebles, } \\
\text { etcétera) }\end{array}$ & 15,4 & 17,9 & 19,1 & 9,7 & 3,5 & 1,0 & 2,2 & 0,7 \\
\hline Fraude y estafas sin violencia & 12,9 & 14,9 & 18,8 & 10,5 & 4,5 & 2,0 & 2,3 & 0,4 \\
\hline Robo coches & 17,1 & 20,1 & 17,7 & 9,3 & 2,6 & 0,6 & 1,6 & 0,4 \\
\hline $\begin{array}{l}\text { Atraco a mano armada en vivienda con heridas o lesiones } \\
\text { graves a usted o alguno de sus familiares ......................... } \\
\text { Atraco a mano armada en la calle con heridas o lesiones }\end{array}$ & 0,8 & 2,6 & 7,3 & 15,7 & 14,6 & 10,7 & 18,9 & 5,0 \\
\hline graves a usted $o$ alguno de sus familiares ......................... & 0,6 & 2,0 & 5,5 & 14,8 & 15,5 & 11,9 & 20,3 & 5,2 \\
\hline 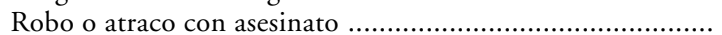 & 0,2 & 0,2 & 0,3 & 2,3 & 6,3 & 9,0 & 36,22 & 21,3 \\
\hline Violación & 0,4 & 0,3 & 1,3 & 6,2 & 8,2 & 10,3 & 34,3 & 14,7 \\
\hline 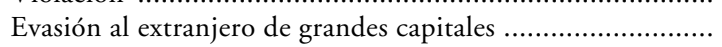 & 2,1 & 2,3 & 5,5 & 12,5 & 13,1 & 9,9 & 17,0 & 1,6 \\
\hline $\begin{array}{l}\text { Tráfico en la calle de heroína en pequeña escala, por pape- } \\
\text { linas }\end{array}$ & 5,3 & 8,0 & 9,2 & 10,2 & 9,0 & 5,5 & 19,3 & 4,9 \\
\hline
\end{tabular}

FUENTE: Encuesta CIS E. 1.708-1989. 
Ahora bien, y por lo que respecta a este último supuesto — pena de muerte- hay que tener presente que, como diversas investigaciones han demostrado, cuando se pregunta la opinión respecto a la pena de muerte sin ninguna matización, los entrevistados se manifiestan mayoritariamente en contra de su aplicación. Pero cuando se pide la opinión sobre la aplicación de la pena de muerte en ciertas situaciones, se observa que esta misma opinión pública es mucho más controvertida, hasta el punto de que predomina ligeramente la proporción de los que se muestran a favor de la aplicación de la pena de muerte en los casos de atentados terroristas con víctimas, asesinato con violación o asesinato de una menor (véase cuadro 11). No obstante, conviene resaltar que la actitud favorable a la pena de muerte en estos supuestos aumenta con el conservadurismo ideológico de los entrevistados.

\section{CUADRO 11}

Me ha dicho usted que está... a favorlen contra... de la pena de muerte. $Y$ en estas situaciones concretas que le voy a citar, ¿estaria usted a favor o en contra de la aplicación de dicho castigo?

\begin{tabular}{|c|c|c|c|}
\hline & A favor & En contra & Duda \\
\hline Asesinato en general .......................... & 34,9 & 50,2 & 7,8 \\
\hline 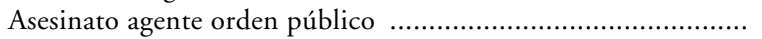 & 35,8 & 49,2 & 7,3 \\
\hline 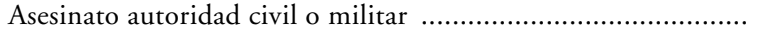 & 36,1 & 48,6 & 7,6 \\
\hline Asesinato con violación .................... & 44,9 & 42,0 & 6,3 \\
\hline 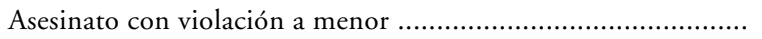 & 47,7 & 39,0 & 6,7 \\
\hline Atentado terrorista que cause víctimas inocentes ......................... & 47,3 & 39,3 & 6,3 \\
\hline 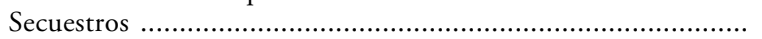 & 10,4 & 76,3 & 5,7 \\
\hline Robo de grandes valores (tesoros, obras de arte) ............................ & 5,5 & 82,5 & 4,1 \\
\hline
\end{tabular}

FuENTE: Encuesta CIS E. 1.708-1987.

Por último, queremos señalar la generalizada aceptación de la cárcel como medida eficaz para controlar la delincuencia y de la idea de rehabilitar al delincuente. La población está sensibilizada ante los males que aquejan a las instituciones carcelarias, sus deficiencias estructurales de medios materiales y humanos que hacen casi imposible llevar a cabo el mandato constitucional recogido por la propia legislación penitenciaria: rehabilitar y reinsertar al delincuente. En 1988, E. 1.736, la opinión sobre la situación de las cárceles españolas es más bien negativa (el 28,6 por 100 de los encuestados sostenían esta apreciación), y esa opinión parece ser predominante en todos los segmentos sociales, siendo peor cuanto menor es la edad del entrevistado y más alta su posición social. Asimismo, más del 30 por 100 de los encuestados consideran que 
hay que ser más duros en la ejecución de la pena privativa de libertad, sobre todo, porque existe la creencia generalizada de que los delincuentes «entran por una puerta y salen por otra». Incluso muchos entrevistados creen que los presos reciben un trato más bien blando $(27 \text { por } 100)^{13}$.

\section{A MODO DE CONCLUSION}

El derecho vigente ordena y protege cierta forma de vida social y tiene, para ello, capacidad coactiva en determinados casos. La ley no sostiene la Justicia, sino el orden. Y puesto que la desviación de las normas tanto de forma individual como colectiva supone una falta de lealtad al orden social imperante, la ley actúa garantizando la ejecución de actividades destinadas a restablecer el orden. Ahora bien, la actuación de las instituciones legales puede servir tanto para la consolidación del orden (por ejemplo, estimulando la reacción social contra el que transgrede las normas) como para ahondar en la crisis institucional si no aciertan en sus actuaciones o los ciudadanos no las entienden y aprueban $^{14}$.

En el estudio del caso español hemos pretendido contrastar algunas de estas premisas, ensayando un intento de elucidación de las relaciones entre el delito, la ley y su sanción penal.

De dicho análisis se desprende que existe un desencanto generalizado sobre el funcionamiento de los aparatos de Justicia. La Justicia está en crisis debido al propio funcionamiento de la misma en sus aspectos más cotidianos y procesales, como la lentitud en los procesos. No obstante, los españoles piensan que hay que obedecer las leyes y que la ley es imprescindible para el funcionamiento de la sociedad. Justifican su obediencia porque sin ley no habría orden. $\mathrm{Y}$ esto ocurre independientemente de que un sector importante de la opinión pública considere que la ley es arbitraria e injusta en muchos casos.

Por otra parte, la inseguridad ciudadana, entendida como miedo al delito y

${ }^{13}$ Esta apreciación se aleja de las contempladas por los redactores del Informe Anual de la Asociación Pro-Derechos Humanos en 1990, que resumían la situación de la cárcel de forma muy diferente. "Las condiciones de vida de las prisiones son muy deficientes en general. Son muy numerosos los reclusos que están muchas horas sin hacer nada, excepto permanecer en los patios. Existe una gran escasez de programas de preparación para la vida en libertad. Se da prevalencia al factor carcelario sobre el reeducador. Es cada vez más urgente la humanización del ámbito penitenciario, y hay que replantearse desde su raíz las estrategias adecuadas para la reinserción.» Informe Anual Asociación Pro-Derechos Humanos, Madrid, 1990, pp. 37-38.

${ }^{14} \mathrm{La}$ cuestión del orden jurídico tiene una marcada relación con el actual debate sobre la legitimidad y la crisis de legitimidad de las sociedades occidentales. La legitimidad no puede entenderse sólo como un criterio de evaluación subjetivo, y menos como una fórmula de procedimiento, aunque sea de procedimiento democrático. La legitimidad, en tanto que evaluación de los sujetos hacia la sociedad política en que viven, no puede ser comprendida adecuadamente si no se la sitúa en relación con la evolución de la sociedad misma, con el marco de valores prioritarios en ella y con los criterios de identidad en los que históricamente va a encarnarse. 
al delincuente que perturba la paz cotidiana, se presenta ante la opinión pública como uno de los grandes problemas de la sociedad actual y es, a su vez, una de las causas de la falta de credibilidad de la Justicia y de la aparición de tendencias autodefensivas de parte de la población.

Haciendo referencia a los delitos y las penas, podemos indicar que existen en nuestro país dos discursos claramente distanciados. Tenemos, por una parte, el discurso que llamaríamos reaccionario o conservador, en el que se concentran los partidarios de una justicia retributiva, defensores incluso de la restauración de la pena de muerte. Por otro lado estaría el discurso que denominamos progresista, en el que al hablar del delito se incluye la causalidad social del mismo; igualmente se cuestiona la operatividad de las penas privativas de libertad y se buscan medidas alternativas.

El temor al delito impacta en la cultura legal generando una mayor demanda de endurecimiento punitivo. Es posible que los reclamos de castigos más severos a los delincuentes resulten incentivados por la percepción de un Estado que no cumple, o que cumple a medias, su papel en el mantenimiento del orden social, pero su crecimiento representa una amenaza para la estabilización de los valores democráticos.

La experiencia democrática ha permitido poner en cuestión la forma tradicional de administrar Justicia, lo que no es poco, pero ahora queda el paso decisivo de afrontar de manera profunda su transformación, comenzando por la redacción definitiva del Código Penal de la democracia.

El cambio social implica un riesgo, pero no cambiar implica un riesgo aún mayor.

\section{BIBLIOGRAFIA}

Andrés IbáNEzZ, P. (1988): «Poder judicial y Estado de derecho, la experiencia de Justicia Democrática», en Justicia/Conflicto, Madrid, Tecnos.

Andrés IbáNez, P., y Pérez Mariño, V. (1991): "La justicia: entre la Constitución y la crisis», en J. Vidal-Beneyto (ed.), España a debate, Madrid, Tecnos.

Arnaud, A. (1981): Critique de la raison juridique, París, Librairie Générale de Droit et Jurisprudence.

AYLLON, J. (1990): «Mentalidad social y jurisprudencia: análisis empírico de una disfuncionalidad/social», Oñati, Proceedings, 2, pp. 67-76.

BARATA, A. (1986): Criminología crítica y critica del derecho penal. Introducción a la sociología jurídico-penal, México, Siglo XXI.

- (1989): «El debate sobre la despenalización. Introducción a una sociología de la droga», Debats, 29.

Bergalli, R. (1984): Estado democrático y cuestión judicial. Vias para alcanzar una auténtica y democrática independencia judicial, Buenos Aires, Depalsa.

BRILlon, Yves (1985): "Images du systhème de justice criminelle et réactions du public», Année Sociologique, 55.

Bustos RAMírez, J. (1987): Control social y sistema penal, Barcelona, PPU.

CIRES (1993): La realidad social en España 1991-92, Madrid, Ediciones B., S. A. 
CENTRO DE INVESTIGACIONES SOCIOLÓGICAS: Encuestas y barómetros de opinión pública (varios años). Justicia:

- Estudiantes de derecho, 1.222.

- Abogados y jueces, 1.244 .

- El sistema judicial, 1.305.

- Actitudes y opiniones de jueces y magistrados, 1.372 .

— La justicia ante la opinión pública, 1.708.

- Imagen del jurado, 1.847.

Delincuencia, seguridad ciudadana:

- Criminalidad, 1.149.

- Victimización, 1.152.

- Victimización y droga, 1.206.

- Inseguridad ciudadana (I), 1.251.

- Inseguridad ciudadana (II), 1.313.

Barómetro marzo 1985, 1.453.

Cuestiones de actualidad: terrorismo y seguridad ciudadana, 1.714.

Barómetro marzo 1988, 1.736.

Actitudes de los españoles ante la justicia penal, junio-julio 1992, 2.015.

CoHen, S. (1985): Social control and the state, Oxford, Basil Blackwell.

FOUCAUlt, M. (1980): La verdad de las formas juridicas, Barcelona, Gedisa.

Garzbim, A. (1986): "Evaluación ciudadana de los procesos judiciales», Anuario de Sociología y Psicología Jurídica, 12, pp. 77-98.

Garzón, A., y SEOANE, J. (1986): «Evaluación ciudadana de los procesos judiciales: un cuestionario de actitudes judiciales», Anuario de Sociología y Psicología Jurídica, 12, pp. 77-98.

Habermas, J. (1981): Historia y critica de la opinión pública, Barcelona, Gustavo Gili.

Hulsman, L., y Bernat de Celis, J. (1984): Sistema penal y seguridad ciudadana. Hacia una alternativa, Barcelona, Ariel.

Jiménez Burillo, F., y Clemente, M. (comps.) (1986): Psicología social y sistema penal, Madrid, Alianza Universidad Textos.

LAmo De Espinosa, E. (1989): Delitos sin víctima. Orden público y ambivalencia moral, Madrid, Alianza Universidad.

MacCormick, N. (1982): Legal right and social democracy: Essays in legal political philosophy, Oxford, Clarendon Press.

Monzón, C. (1987): La opinión pública. Teoría, concepto y método, Madrid, Tecnos.

Neumann, F. (1986): The rule of law: Political theory and the legal system in modern society, Heidelberg, Berg.

Ortet-Fabregat Géneros-Pérez, J. (1992): «An assessment of the attitudes towards crime among professionals in the criminal justice system», British Journal of Criminology, 32, 2, pp. 193-207.

ReSTA, E. (1984): L'ambiguo diritto, Milano, Franco Angeli.

Robert, P. (1990): «El ciudadano frente a la justicia penal: actitudes y esperanzas», Papers, 5, pp. 9-18.

Robert, P., y Faugerón, C. (1978): La justice et son public, Masson, Suisse.

Taylor, I.; Walton, P., y Young, J. (1977): Criminología crítica, México, Siglo XXI.

Tomas, Ch. W.; CAge, R. J., y ForTes, S. C. (1976): «Public opinion on criminal law and legal sanctione: an examination of two conceptual models", Journal of Criminal Law and Crimino$\log y, 67, \mathrm{I}, \mathrm{pp} .110-116$.

TOHARIA, J. J. (1987): «Pleitos tengas!...» Introducción a la cultura legal española, Madrid, Centro de Investigaciones Sociológicas.

— «Quinto barómetro de opinión pública», Poder Judicial, 19, pp. 89-126.

TREVES, R. (1978): Introducción a la sociología jurídica, Madrid, Taurus.

VARIOS (1988): Cesar Beccaria and modern criminal policy, Milán.

Versele, S. C. (1973): Justice penale et opinion publique, Editions de l'Université de Bruxelles. 


\title{
RESUMEN
}

Este artículo tiene por objeto estudiar las opiniones de los españoles en torno a un cierto número de cuestiones de política criminal en el período de transición y consolidación democrática, con especial consideración a la valoración que hacen los ciudadanos de la Administración de Justicia, la percepción de la evolución de la criminalidad y las medidas que consideran más eficaces para paliar esta situación. Igualmente vamos a intentar penetrar en la conciencia penal de los españoles, a fin de evaluar el grado de permisividad o severidad ante determinados comportamientos delictivos. Por último, trataremos de sintetizar estas aportaciones dentro del marco general de la crisis de legitimidad de las instituciones públicas.

En todos los casos, y siempre que lo permitan los datos, trataremos de presentar una realidad diacrónica y sincrónica del estado de la cuestión.

\begin{abstract}
The aim of this article is to study the opinion of spaniards regardins a certain number of issus on criminal policy in the period of transition and democratic consolidation, with due regard to the evaluation the citizens make of the administration of justice, their perception of the evolution of criminality and the measures they consider most effective to curb the situation. We shall at the same time try to delve into the social consciousness of the spaniards in orden to evaluate its level of permissiveness or strictness in the face certain criminal behaviours. Finally, we shall attempt to synthesize these contributions within the general framework of the crisis of legitimacy in public institutions.

In all these cases and as long as data permits us, we shall try to paint a diachronic and synchronic reality of the state of the issue.
\end{abstract}


TEXTO CLASICO 